Academy of Management Annual Meeting Proceedings includes abstracts of all papers and symposia presented at the annual conference, plus 6-page abridged versions of the "Best Papers" accepted for inclusion in the program (approximately 10\%). Papers published in the Proceedings are abridged because presenting papers at their full length could preclude subsequent journal publication. Please contact the author(s) directly for the full papers.

\section{A supply-side story for a threshold model: Endogenous growth of open innovation communities}

Francesco Rullani and Lorenzo Zirulia

Published Online: 23 Feb 2018

https://doi.org/10.5465/ambpp.2013.16674abstract

\section{Abstract}

This paper takes an institutional look (as Dasgupta and David do for Science and Technology) at open collaborative innovation communities (Community). Drawing from the community of practice literature to describe communitarian social processes, we develop a model in which Community is confronted with Technology with respect to its ability to attract researchers. We find that the number of individuals that initially chooses each institution is crucial, as it determines a threshold size that divides the realm of communities doomed to remain small from the set of communities that are able to grow endogenously fast and large. We examine how communities can reach that threshold and discuss this result in light of the strategies firms that invest in communities can apply to exploit this effect. We also discuss how changing the level of openness protection and the importance of the social environment in Community affect innovativeness and find that what really solves any ambiguity in this sense is the way Technology, not Community, is structured. We finally discuss the policy implications of this effect.
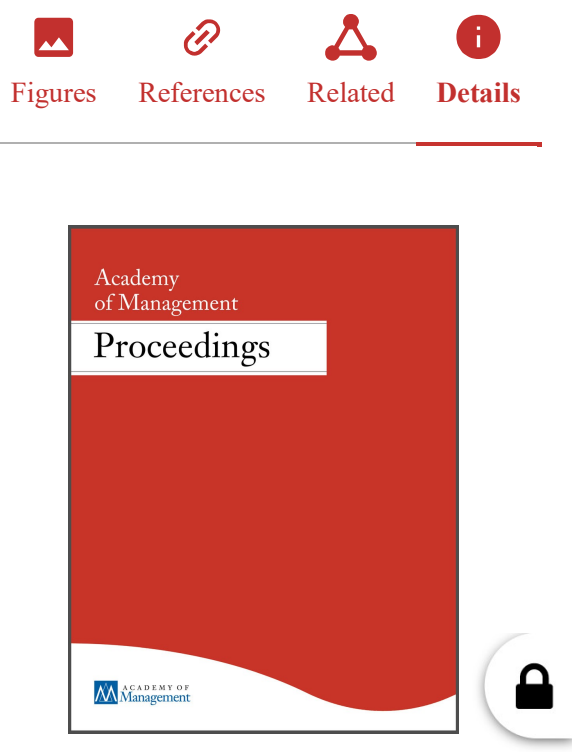

Vol. 2013, No. 1

\section{Permissions}

\section{Metrics}

Downloaded 0 times in the past 12 months

\section{History}

Published online 23 February 2018

Published in print 1 January 2013

\section{Information}

Copyright of Academy of Management Journal is the property of Academy of 


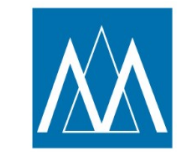

A C A D E M Y O F
Management

Academy of Management

555 Pleasantville Road,

Suite N200

Briarcliff Manor, NY

10510-8020, USA

Phone: +1 (914) 326-1800

Fax: +1 (914) 326-1900

Privacy Policy Logo Use

(C) 2020 Academy of Management

Powered by Atypon ${ }^{\circledR}$ Literatum 